\title{
Leadership communication styles: a descriptive analysis of health care professionals
}

\author{
This article was published in the following Dove Press journal: \\ Journal of Healthcare Leadership \\ 25 June 2012 \\ Number of times this article has been viewed
}

\section{Rebekah Rogers \\ School of Communication, East Carolina University, NC, USA}

Correspondence: Rebekah Rogers I640 B Brook Hollow Dr, Greenville, NC 27834, USA

Tel +l 2529177526

Fax + I 252328 I509

Email rogersr@ecu.edu
Abstract: The study of leadership in health care is important to examine for many reasons. Health care leaders will inevitably have an impact on the lives of many people, as individuals rely on physicians and nurses during some of the most critical moments in their lives. This paper presents a broad overview of a research study conducted over the past year and highlights its general conclusions. In this study, I examined the leadership styles of health care administrators and those of physicians and nurses who chair departments. Thorough analysis yielded three clear themes: viewpoints on leadership, decision making, and relationships. Physicians' viewpoints on leadership varied; however, it was assumed that they knew they were leaders. Nurses seemed to be in a category of their own, in which it was common for them to use the term "servant leadership." Results from the hospital administrators suggested that they were always thinking "big picture leadership." Leadership is a working component of every job and it is important for people to become as educated as possible about their own communication style.

Keywords: leadership, communication, health care

\section{Introduction}

The study of leadership in health care is important to examine for many reasons. Health care leaders will inevitably have an impact on the lives of many people, as individuals rely on physicians and nurses during some of the most critical moments in their lives. This paper presents a broad overview of a research study conducted over the past year and highlights its general conclusions. In this study, I examined the leadership styles of health care administrators and those of physicians and nurses who chair departments. All of the study participants were employees in the health sciences division of a large Southeastern university in the USA. Before conducting the study, I determined through research that there are many types of styles that leaders can embody, including transformational leadership, transactional leadership, and servant leadership. I will provide more insight into what each of these different types of leadership entails in the literature review. I will also discuss the relationship between health care and leadership, as well as the role of physicians as leaders, nurses as leaders, and hospital administrators as leaders.

This research aimed to elucidate the importance of linking leadership styles to individual professions, and in this context, specifically investigated the health care profession. To this end, the following research questions (RQs) were advanced:

RQ1: What are the leadership approaches or philosophies reported by doctors, nurses, and hospital administrators? 
RQ2: Is there a leadership approach that is found to be common among health care professionals?

Effective communication and leadership styles are essential in the workforce. Individuals who show superb communication and leadership skills should be able to find success in their organization at a faster pace than those whose communication and leadership skills are lacking. Additionally, the study of one's own leadership style is important in order for individuals to be able to grow professionally, personally, and developmentally. Leadership is a working component of every job, regardless of whether one is employed as a factory worker, academician, or chief executive officer of a large corporation. In short, people want to work for and with people who are skilled in communication and who have strong professional and personal leadership qualities. Therefore, the current research is important for many practical reasons. I believe it is critical for individuals to take this information and apply it to their own working lives. I was able to gain valuable insights into styles of leadership through this research, and the research was beneficial to the participants because they learned about their own leadership style and were able to draw general conclusions in relation to their profession, personality, and demeanor. They also gained valuable insights into the way they work with others. Individuals are becoming more aware of their leadership styles and the way they communicate through feedback from others. In addition to the individual level, this research can have an impact at a global level. Through the current research, it is my hope that people will see the value in learning more about their own leadership styles and ideologies.

\section{Background}

\section{Theory}

In this study, the style approach was used to guide the research. In this approach, the focus is on the behavior of the leader; in fact, it centers exclusively on what leaders do and how they act. Within the style approach framework, researchers have suggested that there are two general kinds of behaviors: task behaviors and relationship behaviors. Task behaviors assist in goal accomplishment such as helping group members achieve their objectives. Relationship behaviors help subordinates feel comfortable with each other, with themselves, and in their specific situation. According to Northouse, "the central purpose of the style approach is to explain how leaders combine these two kinds of behaviors to influence subordinates in their efforts to reach a goal." I used this approach because of the assumption that every participant has a different leadership style that affects what they do and how they act. In addition, the different types of styles are defined by a combination of exhibited behaviors, and the easiest way to observe those behaviors is through an interview. Though the style approach is being used as a theory, Northouse noted that it is not a perfect indicator of strong leadership behavior using a structured and organized approach because it does not have a set rubric for determining the desired outcome. ${ }^{1}$ Instead, Northouse stated:

The style approach provides a framework for assessing leadership in a broad way, as behavior with a task and relationship dimension. The style approach works not by telling leaders how to behave, but by describing the major components of their behavior. ${ }^{1}$

The style approach is a dynamic approach, because it looks at the task and relationship behavior of the leader, and is a reminder that actions result from a combination of the two. Different situations call for different measures because in some cases the leader may need to be more task oriented in their behavior, and in other situations, the leader may need to be more relationship oriented. Similarly, some subordinates need to be given specific directions in order to perform their job well and others may need an environment of support and praise. Through the leaders knowing how their subordinates function best, they can perform their jobs better and there will be a greater sense of job satisfaction overall. Most importantly, Northouse states that the style approach "reminds leaders that their impact on others occurs through the tasks they perform as well as in the relationships they create." Using the style approach in this study allowed me to be open to obtaining a wealth of descriptive data that is of a true qualitative nature.

\section{Literature review}

\section{Leadership and management}

The existing literature on leadership and communication styles presents a rich overview of this critical phenomenon and its application to the health care profession. When exploring leadership communication styles, it is important to carefully differentiate between the terms "leading" and "managing." Curtis et al suggest that managers administer, maintain, control, have a short-term view, and initiate. ${ }^{2}$ Kotterman further contends that managers tend to "plan and budget," as well as focus on narrow objectives in order to "maintain order, stabilize work, and organize resources." ${ }^{3}$ Additionally, managers often seek to "control and problem solve" as they "produce standards, consistency, predictability, and order."3 Curtis et al recognize that leaders innovate, develop, inspire, 
challenge the status quo, and focus on a long-term vision. ${ }^{2}$ Kotterman "sees management as dealing with procedures, practices, and complexity and leadership as dealing with change." ${ }^{3}$ The focus of this analysis is on the leadership communication styles of health care professionals; therefore, it is critical to understand a variety of approaches to effective leadership. Specifically, this research examines how transformational leadership, transactional leadership, and servant leadership apply to health care professions. Each of the styles will be explained in detail within the following review of key literature concepts that impact this area.

\section{Transformational leadership}

James McGregor Burns' Leadership ${ }^{4}$ is considered to be the seminal text in the field of leadership studies. ${ }^{5}$ Transformational and transactional leadership emerged as the dominant leadership framework in the 1990s, and in 1978, Burns defined transformational leadership as the following: "wherein one or more persons engage with others in such a way that leaders and followers raise one another to higher levels of motivation and morality." In Burke and Cooper, Avolio and Yammarino state that transformational leadership consists of the following key factors: "One, charisma, instills faith, pride, and respect for the leader. The second, individualized consideration, involves treating all staff as respected individuals with unique needs. The third, intellectual stimulation, encourages staff to think in new ways." According to Burke and Cooper, these types of leaders closely identify with their subordinates and with the purpose of the organization. ${ }^{6}$ Motivation also plays a significant role for transformational leaders, especially since it leads to success in their position and an optimistic outlook on the organization. ${ }^{6}$ Additionally, transformational leaders are not set in their ways. They are open to change and often appreciate a creative approach to problem solving and teamwork. While this approach can be risky at times, transformational leaders excel using this style of leadership. ${ }^{6}$

\section{Transactional leadership}

Transactional leadership occurs when a person takes the initiative in making contact with others for the purpose of an exchange of valued items. The trade could be financial, social, or emotional in nature: an exchanging of a product for money; the trading of ideas among businessmen; or even providing a listening ear to those in need. ${ }^{5}$ Burke and Cooper stated that "transactional leadership has two components: the transactional leader exchanges rewards contingent upon the exhibition of desired behaviors and results, and intervenes when performance falls short."' Burke and Cooper also noted that transactional leaders are different from transformational leaders in a fundamental sense: they work within the boundaries and the existing standards of the organization. ${ }^{6}$ Few risks are taken and the focus of the work is on efficiency, control, stability, and predictability. ${ }^{6}$

While transformational and transactional leaders are different, it is important to know that they are also complementary in nature. Both styles may be associated with the achievement of desired performance objectives. It is clear that leaders can function using both styles cooperatively and can augment each other on the job. ${ }^{6}$

\section{Servant leadership}

The term "servant leadership" was coined by Robert Greenleaf in his influential 1970 essay "The servant as leader." Greenleaf believes that these types of leaders focus on the service aspect first, as they have a natural tendency to help others. Once service is achieved, the individual aims to lead as a result of this achievement. Greenleaf writes that the best way to determine whether a person is a servant leader is to identify whether they grow as a person, become healthier, and are likely to develop an autonomous and selfless desire to serve others. ${ }^{5}$ Servant leadership is a long-term, transformational approach to life and work. It is an ever-changing process with the goal of creating change throughout society. Spears believes that the following characteristics are central to the development of servant leaders: listening, empathy, healing, awareness, persuasion, conceptualization, foresight, stewardship, commitment to the growth of people, and building community. ${ }^{5}$ Spears believes that these ten characteristics "serve to communicate the power and promise that this concept offers to those who are open to its invitation and challenge." 5

\section{Health care and leadership}

The health care industry is constantly advancing. In the past decade, the health care business has become one of the most powerful in our society, providing a significant number of jobs and critical medical services for citizens. The health care industry is complex and multifaceted. ${ }^{7}$ Due to the complexity of the system, changes in health care have left leaders weary and doubtful of their ability to rebuild trust and provide their organizations with a sense of direction. Dye gives an example of a common sentiment among health care leaders:

The stress, the lack of clarity, changing our vision every two to three years, our constant reengineering and restructuring - all this is taking its toll on our leadership. We are all physically and mentally exhausted and some of us are burned out. It's not fun anymore. ${ }^{8}$ 
In order for health care workers to operate efficiently, they must have effective leadership, and the health care leaders of today face challenges due to the increasing complexities arising in the industry. These challenges will continue to evolve for years to come. Twenty-five years ago, hospitals operated solely to provide care for patients, and their leaders did not have to deal with multiple business lines. "The more complex the system, the less efficient its operation," is an adage that is true of the current health care system. ${ }^{7}$ Researchers are realizing that employee commitment and loyalty are at their lowest, and that health care executives, physicians, and patients today are generally "dissatisfied with the management in the industry." ${ }^{.7}$ Leaders are an essential component of successful health care initiatives. Patients turn to physicians, nurses, and hospital administrators for guidance and direction. Souba wrote that "Health care today needs ... a new kind of leadership; strong leaders and a new cultural context in which they can lead." The following paragraphs explain the importance of leadership among physicians, nurses, and hospital administrators.

\section{The physician as leader}

Physicians are part of an expert culture. An essential element of an expert culture is that the individuals with all the knowledge make all the decisions, issue by issue, from the perspective of how decisions will personally affect them. Souba wrote that "today's medicine structure incents physicians and other leaders to focus on knowing, having (titles, power) and doing (out-performing) such that personal reward is often valued above service to others." Bujak, a physician, says that "when I listen to physicians speak, I notice that they infrequently speak in the plural. Physicians usually say "I" and "me," but rarely "we" and "us." 10 This study suggests that physicians do not have a collective identity. ${ }^{10}$ Interestingly, Palmer et al found that "doctors see themselves as 'coordinators', 'team workers' and 'company workers', which means that they want to communicate, be organized, and avoid friction." 11 They also found that physicians "do not show strong tendencies to be enterprising, creative, or critical thinkers." ${ }^{11}$ Physicians described teamwork as the following:

Physicians' definition of teamwork is like the game of golf. Members of a golf team are seeded in a way that reflects their individual competency. The best member of the team is seeded number one. The next best member is seeded number two, and so on. When teams compete, the respective seeds compete against each other. Winning an individual match accrues points for the team, and, at the end of the day, the team that amasses the most points wins the competition. What, then, must an individual do to contribute to the likelihood that his team will win the competition? The answer is to win his individual match. If each member wins his individual match, the team wins. If the team loses, the members who have lost their individual matches are blamed. Teamwork to the physician is a zero-sum game in which the whole equals the sum of the parts. ${ }^{10}$

Bujak compares teamwork within the health care organization to volleyball, saying "The roles of the team members are clear and interdependent. In this case, the whole can exceed the sum of its individual parts. The functionally best teams are not always comprised of the best individual players." 10

When it comes to physicians and decision-making, Bujak concluded that physicians tend to focus on outcomes. ${ }^{10}$ If success was achieved, how it was achieved is irrelevant because the end justifies the means. This is the essence of distributive justice. In contrast, the culture of the health care organization demands a more procedural justice that focuses on the process rather than the end conclusion. According to Bujak, the outcomes of the situation are reliant on whether physicians personally and actively participate in the process to achieve the desired outcome. ${ }^{10}$ Individual opinion being heard in the process is important as well. Solutions are only appropriate if the right voices are heard from the appropriate sources. ${ }^{10}$ According to Bujak, this time-consuming requirement for inclusiveness irritates physicians, whose philosophy is "if you know the answer, just do it yourself! Stop wasting time!" 10 However, in a health care organization, imposing a decision without following the appropriate steps or gaining the acceptance of the whole group only ensures that the measure will be resisted. Bujak recognized that "while physicians advocate for distributive justice when they are the ones giving the orders, they too demand procedural justice when others give orders to them." ${ }^{10}$ Bujak also discusses what motivates physicians:

Experts determine success by outperforming the competition. Achievement, taking risks, stamina, intense focus, quick decision making, and personal accountability are characteristic. Physicians are strongly vision or goal directed. They are not usually motivated by mission. Frequently, hospital administrators and their governing boards try to leverage the medical staff's behavior by suggesting that they have lost their professional "soul" because they do not support the mission of the healthcare organization. ${ }^{10}$ 
However, the health care organization and the physician typically have different missions. Bujak noted that the most important action for creating an effective health care organization is to link the goals of individual physician practitioners with the actual needs of the health care setting: if doctors can see a direct connection between their success and the goals of the organization, then a positive working relationship can occur; if not, then the vision will fail and self-interest will take over. ${ }^{10}$

Physicians tend to resist collaboration and teamwork. They were trained to function under their own self-control, and partnership is a difficult quality to learn after many years of operating alone. According to Bujak:

Healthcare is a culture of personal accountability in which the attending physicians bear the ultimate responsibility. In this context, one can quickly appreciate why physicians are taught to trust no one. In addition, physicians are usually highly competitive people; obtaining a medical degree is difficult without having been successfully competitive from an early age. Highly competitive people are predisposed not to trust. Competitive individuals are prone to see the world as a zero-sum game. If you win, I might lose. If your slice of the pie enlarges, mine might become smaller. ${ }^{10}$

For this reason, health care organizations that seek to collaborate with physicians form their relationships based on negotiations. Bujak confirms that one can enter negotiations by adopting one of four postures: competition, accommodation, compromise, and collaboration. ${ }^{10}$ Highly competitive physicians play a win-lose game. Physicians are typically skeptical of engaging in collaborative behavior, or win-win negotiations, because collaboration requires trust and highly competitive physicians are predisposed not to trust. Palmer et $\mathrm{al}^{11}$ believe that physicians tend to operate under a transactional leadership style. They noted that the physicians' favoring of the transactional leadership style "correlates with the observation that their team preferences are for accepting and working within the system as it is (mostly transactional), rather than for making changes and shaping the future (more transformational)." "It seems auspiciously evident that physicians are aware of their high intelligence, in most cases, and often believe they can do anything without ample practice. According to Bujak, "in physician training, 'See one, do one, teach one' is frequently repeated. This attitude can foster a sense of arrogance and self-confidence that oversimplifies and underestimates the contributions of others who contribute to patient care;"10 as such, physicians are expected to have all the answers, bear the ultimate legal responsibility, and meet the expectation of perfection. It is not surprising, therefore, that physicians have a strong need to be able to predict and thereby control their environment.

Health care organizations recognize the importance of identifying physician leaders and investing in their leadership potential, as seen in Bujak:

Moving from positions of informal leadership to positions of formal leadership within the organization is a transformative journey. Those who rise to positions of informal leadership do so because they are eloquent spokespersons for the shared needs of their constituency. However, when moving into positions of formal leadership, the individual can never again be "one of the boys." For formal leaders, the mission of the organization must supersede the needs of any one individual. As physician leaders begin to acquire a systems perspective, appreciate the organizational consequences, they also begin to apply a vocabulary and share a perspective that is foreign to the narrow self-interest of their former constituents who, at that point, reject them as having gone over to "the dark side." 10

Souba discussed the importance of physicians understanding their need for "being," as this understanding could lead to a greater development and fulfillment of their leadership. ${ }^{9}$ Souba wrote that the "being of a leader as the basis for what leaders know, have, and do - is central to restoring medicine's long standing ethical underpinnings." ${ }^{\text {"9 }}$ In further comprehension of one's being, Souba contended that greater understanding of oneself can be accomplished through "four ontological pillars - awareness, commitment, integrity, and authenticity." The leadership potential of a physician should begin in the early stages of his or her career; in other words, medical schools should begin teaching this practice. It is clear that investing in the leadership growth of a physician early on will allow him or her to acquire the necessary skills to function as a collaborative, open-minded leader.

\section{The nurse as leader}

Nursing and leadership have been researched extensively. According to Dirschel, "leadership in nursing is a goal, vision, and expectation for all professional nurses in any form of practice."12 Ultimately, all forms of nursing leadership must result in excellent patient care and outcomes. Curtis et al highlighted the importance of effective leadership from not only those individuals who are designated leaders in nursing, but also the importance of effective leadership from students and from all levels between: "It seems logical to conclude that the development of excellence in nursing leadership should, therefore, begin at the earliest stages of basic nursing education 
and training." ${ }^{.2}$ All forms of nursing leadership must also create an environment that supports and encourages evidence-based nursing practice, which is essential for the practice of nursing at the cutting edge of recognized standards. Dirschel's views on nursing are clear in the following:

The nurse leader in the institution is the force behind clinical practice in the nursing role. Nurse leaders being the vision for growth and the power to create the environment needed to preserve and develop the profession. The nurse leader is the visionary and the catalyst who brings power to nursing practice and creates an environment in which innovation and ideas about nursing practice can flourish. The nurse leader must create and orchestrate an environment that supports and encourages excellence in nursing and scholarly, caring practice. The nurse leader has the interesting challenge of creating and maintaining openness in a multidimensional, complex healthcare delivery system and enriching the practice field of nursing for the benefit of the institution. ${ }^{12}$

Dirschel mentions that nursing leadership at the highest level occurs primarily in health care delivery systems and in educational institutions. ${ }^{12}$

The roles of nurses in these two settings are related, but differ significantly. It is important to note that nursing leaders in both of these environments have the same challenges and opportunities to move the profession forward - to move nursing as it is expressed in their institutions to exceed expectations and to move the standards of practice to a higher level. According to Dirschel:

the nursing leader also energizes the dynamics of the other personnel groupings and the vision, mission, structure, and resources of the broader institution. Doing so creates an open, more fluid system throughout the healthcare organization where individuals' resources and roles can work together with greater understanding and cooperation. ${ }^{12}$

Curtis et al believe that nurses embody a transformational style of leadership. ${ }^{2}$ They stated that "creating a warm, safe, and supportive organizational culture and work climate is another initiative that can be used to develop leaders and improve leadership."2 Nurses embodying quality communication also leads to a more seamless approach to leadership in the field of nursing. Finally, when looking at the nurse as a leader, Dirschel concluded that "the roles, responsibilities, resources, and information that shape the persona of the nurse leader and the nurse manager can transport the nurse from bedside to boardroom easily, accurately, and with support and enthusiasm from the staff and leadership alike."12

\section{The hospital administrator as leader}

This study also reviewed the hospital administrator as leader. One might expect a hospital administrator to be extremely power- and status-driven. The leadership development of a hospital administrator must start early in life. Typically, a person must have a long track record of successes to reach a hospital administrator position. The root of this research is embedded in servant leadership: the wanting to give back or contribute in an effort to help others. This feeling of servant leadership begins with the first job or first desire to want to help others. Through the current research, the leadership styles of hospital administrators could be revealed in an effort to make them more self-aware.

\section{Methodology}

This section provides a brief discussion of the methodology I used to study the leadership styles of health care professionals within a health sciences division at a large Southeastern university in the USA. First, I present the interpretive and critical paradigms. Second, I describe the process of conducting the in-depth interviews that were used in the study. Third, I describe the participants and the recruitment process. Finally, I address the methods of data collection, which included in-depth interviews and document analysis.

\section{Interpretive and critical approach to research}

One purpose of this research was to provide a descriptive analysis of the leadership styles observed among health care professionals. I was most interested in learning about the similarities and differences that exist among the leadership styles of physicians, nurses, and administrators. I was also interested in determining whether there are certain leadership traits that make them better suited for their field. In order to achieve these goals, I drew on the interpretive and critical paradigms of research.

One of the basic goals of the interpretative researcher is to gain a deeper understanding of the people and practices under study. Through understanding, I am able to connect to people at a deeper level regarding their idiosyncrasies and knowledge. Other fundamental assumptions that underlie interpretive research are that reality is subjective, researchers seek to gain an understanding through the interpretation of data, knowledge is gained holistically, and learning occurs through observation. ${ }^{13}$

As an interpretive researcher in this project, I embraced subjectivity and realized the necessary uncertainty in field research.

The participants for this study were recruited from the health sciences division of a large Southeastern university 
in the USA. Participants consisted of physicians and nurses who were also department chairs and health care administrators (deans). There were a total of 12 participants, with four individuals from each group. To begin the recruitment process, I initially spoke with an administrator who was in a position that could provide access to the participants I needed. This administrator helped me by sending emails to prospective participants, introducing me to them at events, and also by providing me with names and contact information. Hence, I used a snowball sampling technique; I was able to gain access and credibility with prospective research participants. As noted by Lindlof: "snowball sampling uses a person, usually an informant, as a source for locating other persons from whom a type of data can be generated, who then refer the research to other persons, and so on."13 I contacted the prospective participants through email and attached the informed consent document and institutional review board approval form. The prospective participants then either emailed me back with possible dates for the interview or instructed me to contact their assistant for scheduling purposes. All the twelve participants I contacted agreed to participate.

The interviews occurred between January and March 2010. After each interview was completed, I transcribed the audio recording of the session. Meticulous attention was given to ensure accuracy. Transcribing each interview provided me with the opportunity to listen again using a more analytical approach and also allowed me to interpret the data on a greater level. Kvale emphasizes the importance of the seven stages of the interviewing process to present credible data within this qualitative method. ${ }^{14}$ To follow Kvale's complete interview process, each interview was audio recorded, transcribed, and then re-evaluated to ensure accuracy. ${ }^{14}$ The in-depth interviews followed an interview schedule with approximately 20 open-ended questions (see Appendix A). In each interview, I followed the same interview schedule and asked each question in the same pattern so that the order was the same for all twelve interviews. The duration of each interview varied: one or two lasted for a little over 30 minutes and one lasted for an hour and a half; the remainder were somewhere in between. The interviews yielded 162 pages of transcripts.

Before the formal interview began, I engaged the interviewee in small talk, not only to get to know them better, but also to build rapport for the interview that was going to follow. I wanted the interviewees to feel as comfortable as possible and embody a sense of ease when they answered the questions. When the interviewee would give a short answer to a question, I often asked him or her to provide an example or to expand. For nearly every question, I would use probe questions to provide more of a rich text and understanding, but I was still able to return the interviewee to the original question and central concepts. Using this methodology, the data were collected in order to answer the research questions.

In the following section, I will provide a general overview of the data analysis. In this section, I provide rich text on the central themes that emerged through the in-depth interview process. Each of these themes provides insight into the leadership styles that are found among physicians, nurses, and administrators in the health sciences.

\section{Analysis}

Through the interview process, I was able to explore twelve different health care professionals' perspectives of leadership. From thoroughly reviewing the transcriptions, it was clear that there were many themes that were present in all three groups. The three most evident themes were viewpoints on leadership, decision making, and relationships. Even though I could provide rich text about what the data yielded, I will only present a brief description of what I observed from each of the three participant groups.

After reviewing the transcriptions from the physicians regarding their viewpoints on leadership, it seems that they sent mixed messages about their ideologies. Some of the physicians I interviewed were extremely reflective on their beliefs regarding principles of leadership and others seemed as if they had never given it any thought. One physician said, "Now am I good at [leadership]? I have no idea."

Other physicians seemed to have knowledge of what role leadership can and should play in medicine, but seemed to not think much of it. For example, "In medicine we talk about vision and leadership; I think that's way overrated."

In contrast, some physicians gave well thought-out answers about their ideologies of leadership. Here is an example:

Someone once told me that being a department chair is, especially when the department is made up of doctors who all feel very accomplished in their own right, um, it's a little bit like being the conductor of an orchestra. In other words, I can't play the violin, well in this particular case I can play the violin. But I have certain expectations of the lead violinist and the lead violinist doesn't want to be told in front of the whole orchestra that he or she isn't doing top notch work um and so even though I have a baton and I wave it, I expect the whole orchestra to follow me along and they don't really have to, I mean they can all decide at any moment, they all have free will. I mean they can all play the 
notes of their own volition, they can all start playing whatever they want, they can just play a different tune! And even collaborate to play a different tune, I can be conducting a tune and they are all playing a different tune. So that authority is a little bit of a delusion I would say. The orchestra's power, the conductor's power over the orchestra is a little bit of an illusion. It requires a lot of um um willingness on the part of the orchestra members, same deal.

Another physician shared this viewpoint on leadership:

Another thing about leadership is (sigh) I think leadership is um, is leading, but I think there's a part of leadership that's um, and I try to teach this every day is um, if you really want to be a great leader and you really care about what you're leading, then part of your goal is to build a system so that when you're gone, it doesn't collapse.

Physicians surprised me with their answers with regard to decision-making. Here is an example:

So at the end, I ask, "geez, was that the right way? Did I, did I make the most impact, did I say what was meaningful, will people remember it without the point that I was trying to make, or did I pound my fist in the table too hard or should I have pounded my fist on the table or should I have been less abstract and more straightforward?" Geez louise, I have the most difficult time with my administrative assistant and the administrator for the department and I'm pretty sure I can be pretty direct and get the biggest point in and somehow I don't.

I would have thought that physicians would not secondguess themselves on the major decisions that they make on a daily basis, but it appears that they do. I think it makes them appear more sincere and caring in their profession, rather than having a "this is the way we're going to do it" mentality. Here is another example of physicians' viewpoints on decision-making:

I do try to take the objector's thoughts and try to factor them into my decision making. I never feel like I have to please everyone though. I feel that that is an error that many leaders make is that they think that at the end of the day they have to make everyone happy and that's, I think it's almost always impossible unless you have a very small group and um and nice quote that I can't tell you who said it, but it brings true with is that "if everyone likes your decisions, you're not taking a tough stand on anything." Which means that you don't stand for anything; you're so namby-pamby that everybody likes what you're doing and
I've always felt that I have tough enough skin to be able to weather someone not liking me or liking my decisions and I know that by the end if I stick by them that I'll probably get the outcome I wanted and it's too bad if they didn't like the way it was accomplished.

Even though the physicians' viewpoints on leadership seemed to vary, it is my overall generalization that they all know they are leaders.

Nurses' viewpoints on leadership seemed to be in a category by themselves. The term "servant leadership" came up in dialogue as something to embody. Here is an example:

I try to praise our faculty and staff for their accomplishments. You know, the word "servant leader;" I really feel that that's what I am many times. I try not to take the glory myself, but give praise to the people who are doing all the work that makes us such a very fine college of nursing and we're really well recognized through the state and throughout the nation. So I try to plant seeds that actually other people carry out and we get recognized for those things.

I do think I'm a leader ... I care about the students and I think that that's important in a leader, especially in nursing; I think we tend to be more of a caring person and I think being in a position, in a leadership position that people see that as more of a strength but people may not see it more as a strength. I also feel a leader needs to be able to relate to the people they work with.

The nurses also seemed to want to lead by example. For instance:

Now leadership is when I say, or people say, we say together, okay there's a lot of soldiers coming back with post-traumatic stress syndrome and we have just terrible mental health services in this community and we developed a program of nurse practitioners, they can prescribe drugs, they can see patients, they can you know, that would be very useful so what's it going to take. Well, that's what a leader does; a leader sets the direction.

Hospital administrators tended to think "big picture," based on the answers they provided. These individuals were always thinking of the functionalities of the system as a whole rather than its small components. When asked if they thought they were a leader, this is a response I received: "Have to be, yes. I would not be effective if I didn't think I was a leader in this job."

It seemed that their viewpoint was that if the whole system was operating well, then everything else was too. 
In addition, all the hospital administrators discussed how they were so consumed by meetings during the day that they hardly had enough time to respond to their emails. Below is an example:

I would say a frustrating thing for me is having "think time" because I'm constantly involved in meetings after meetings and I really, to really think visionary you really need blocks of time to think, where do we need to go, what do we need to do and sometimes that can only happen at night after you get home from work and are somewhat exhausted.

This idea of "think time," I believe, is the perfect way to describe this problem. One would assume that senior level administrators would have time in their day to reflect on decisions that were made and to reflect on what reactions they might have to decisions that were made via group consensus. Below are an administrator's thoughts on leadership:

Good leadership is that you have a vision and you successfully achieve it and managing is somebody else having a vision and you helped them achieve their vision through your management.

Hospital administrators seemed to have mature viewpoints on decision making. Here is an example:

I'm not a do it all yourself kind of leader. I'm a big time delegator, which means I try to recruit really capable people or people with really great aptitude and I give them a lot of responsibility and I give them guidance when asked but I try to encourage them to make most of the decisions themselves, so a lot of my decisions that come down are more global things as opposed to more day to day here's what I want you to do today things. And that's the way I prefer it, I think that's the way organizations work best under me.

It appears that the administrators realize that they are not the single source of power and information; instead, they put their trust and faith in people who have been highly trained in their particular field to make the right decisions. Though some might argue that it is risky to put this level of trust and faith in another to make a decision that affects the whole organization, this ability is viewed as strong indicator of true leadership. True leadership is many times about enabling and trusting other individuals and providing them with all of the necessary components to succeed.

\section{Conclusion}

The practical implications of this research are important for all health care professionals. It is evident that physicians, nurses, and administrators must have an increased awareness of self and individual leadership style. Each individual having a better understanding of him or herself and how they are perceived from others may help the overall health of the organization.

In addition, it is important for each of these health care leaders to be engaged in practices of reflection. Bar-On defines self-reflection as "a process of exploring and evaluating our thoughts, feelings, and behavior." 15 Through the process of self-reflection, health care leaders should be able to better access the needs of their organization on a more profound level of engagement. As mentioned earlier, Curtis et al recognized that leaders innovate, develop, inspire, challenge the status quo, and focus on a long-term vision. ${ }^{2}$ From this research, the critical need for these health care leaders to engage in self-reflection to better understand themselves and have "thinking time" to set the direction for the future of their organization is evident. The health of each organization depends upon the health of the leader and his or her greater understanding of self.

\section{Limitations and future research suggestions}

The key concepts presented in this paper have highlighted the general knowledge and understanding of basic leadership ideologies. I have learned a great deal through the course of this year as I have researched communication and leadership, conducted this study, and found key themes throughout the long and rich text. Though this paper is not exhaustive, it provides a general summary and overview of the study and observations I made after completing the transcriptions. There is still more literature that should be reviewed and linked to this study. The data might also yield different results at another university; therefore, the data might not be a predictable indicator of future leadership and communication expectations and values. Additionally, while this study matches specific health professions with selected leadership communication styles, it is important to remember that leaders must be adaptable and flexible. For example, hospital administrators in this study were most closely aligned with transformational leadership; however, it is critical for these leaders to also incorporate other leadership styles based on situational factors. Future research needs to look at the core coursework of nurses, physicians, and administrators in educating them on the principles of leadership and effective communication. Future research could be conducted looking at the stereotypes applied to nurses, physicians, and administrators by subordinates or clients. 


\section{Disclosure}

The author reports no conflicts of interest in this work.

\section{References}

1. Northouse PG. Leadership: Theory and Practice, 3rd ed. Thousand Oaks: Sage Publications; 2004

2. Curtis AE, Vries JD, Sheerin FK. Developing leadership in nursing: exploring core factors. Br J Nurs. 2011;20(5):306-309.

3. Kotterman J. Leadership Versus Management: What's the Difference? $J$ Qual Participation [serial on the Internet]. 2006;29(2):13-17. Available from: http://asq.org/pub/jqp/. Accessed March 23, 2012.

4. Burns MJ. Leadership. New York: Harper \& Row Publishers; 1978.

5. Spears LC. Insights on Leadership: Service, Stewardship, Spirit, and Servant-Leadership. New York: John Wiley \& Sons, Inc; 1998.

6. Burke RJ, Cooper CL. Inspiring Leaders. New York: Routledge; 2006.

7. Dye CF, Gasrman AN. Exceptional Leadership: 16 Critical Competencies for Healthcare Executives. Chicago: Health Administration Press; 2006.

8. Dye CF. Executive Excellence: Protocols for Healthcare Leaders, 2nd ed. Chicago: Health Administration Press; 2000.
9. Souba WW. The Being of Leadership. Philos Ethics Humanit Med, [serial on the Internet]. 2011;6(5):1-11. Available from: http://www. peh-med.com/content/6/1/5. Accessed March 23, 2012.

10. Bujak JS. Inside the Physician Mind: Finding Common Ground with Doctors. Chicago: Health Administration Press; 2008.

11. Palmer R, Cragg R, Wall D, Wilkie V. Team and leadership styles of junior doctors. The International Journal of Clinical Leadership, [online]. 2008;16:131-135. Available from: http://www.radcliffe-oxford. com/journals/J24_The_International_Journal_of_Clinical_Leadership/ default.htm. Accessed March 23, 2012.

12. Dirschel KM, Klainberg M. Today's Nursing Leader: Managing, Succeeding, Excelling. Sudbury: Jones and Bartlett Publishers; 2010.

13. Lindlof T. Qualitative Communication Research Methods. Thousand Oaks: Sage; 1995.

14. Kvale S. Interviews: An Introduction to Qualitative Research Interviewing. Thousand Oaks: Sage; 1996.

15. Bar-On T. A meeting with clay: individual narratives, self-reflection, and action. In: Smith JK, Smith LF, Kaufman JC, editors. Psychology of Aesthetics, Creativity, and the Arts [serial on the Internet]. 2007; 1(4):225-236. Available from: http://www.apa.org/pubs/journals/aca/ index.aspx. Accessed March 15, 2012. 


\section{Appendix \\ Interview questions}

Thank you for agreeing to participate in this study. Since our interview will be recorded, I want to be sure some information is correct. Will you please tell me your name and the current position you hold here at ECU?

*Everything is confidential, your identity, your name.

What issues most affect your daily work life?

Are there any issues that seem to require more negotiation than others?

Can you think of any instances where you needed to exercise your authority in order to get something done? How did you handle it?

What happens if someone disagrees with your decisions?

I know doctors (nurses, administrators) are often thought of by the public as "leaders;" would you characterize yourself as a leader? If so, what do you think makes you a good leader?

When you encounter conflict over or resistance to a goal you are pursuing do you have any set strategies you employ to accomplish your goal? Do the strategies differ according to who is resisting?

Can you recall a particularly challenging event or interaction at work and how you dealt with it?

Would you consider it to have had a good or bad outcome?

Are there situations where you make decisions that others have to follow?

How do you inform others about the decision? How do you enforce it?

How are you informed about others' decisions that affect you?

Do you ever have to do collaborative work in teams or groups? Can you provide an example of how you were particularly valuable to the outcome?

Is there anything else that you want to address about what we have discussed, eg, your position, your role?

If I have any follow-up questions, can I email you?

\section{Publish your work in this journal}

The Journal of Healthcare Leadership is an international, peer-reviewed, open access journal focusing on leadership for the health profession. The journal is committed to the rapid publication of research focusing on but not limited to: Healthcare policy and law; Theoretical and practical aspects healthcare delivery; Interactions between healthcare and society and evidence-based practices;

\section{Dovepress}

Interdisciplinary decision-making; Philosophical and ethical issues; Hazard management; Research and opinion for health leadership; Leadership assessment. The manuscript management system is completely online and includes a very quick and fair peer-review system. Visit http://www.dovepress.com/ testimonials.php to read real quotes from published authors. 